\title{
Pilot-plant cultivation of Streptomyces griseus producing homologues of nonactin by precursor-directed biosynthesis and their identification by LC/MS-ESI
}

\author{
Tomáš Řezanka, Aleš Prell, Jaroslav Spížek and Karel Sigler
}

Precursor-directed biogenetic approach was used to produce a range of nonactin homologues in a $50 \mathrm{I}$ fermentor cultivation of strain Streptomyces griseus 34/249 obtained by UV mutagenesis. The production medium contained sodium propionate, isobutyrate and isovalerate as individual precursors, and $10 \mathrm{~g} \mathrm{I}^{-1}$ Diaion HP20 styrene-divinylbenzene resin that maintains suitable precursor concentration by reversibly adsorbing and releasing it. The produced nonactin homologues were separated on two $\mathrm{C} 18$ reversed-phase liquid chromatography columns in series and analyzed by MS with ESI source in the positive ion mode. Formation of doubly charged ions was suppressed by an excess of $\mathrm{Na}^{+}$ions throughout the process. The production of the homologues increased up to day 5 and then it leveled off. Cultivations with individual precursors yielded a total of 18 nonactin homologues whose spectrum depended on the precursor used. The total production of the homologues was lowered but their spectrum was shifted to higher-molecular-weight compounds.

The Journal of Antibiotics (2010) 63, 524-529; doi:10.1038/ja.2010.93; published online 28 July 2010

Keywords: liquid chromatography/MS-ESI; pilot-plant cultivation; precursor-directed biosynthesisl; Streptomyces griseus

\section{INTRODUCTION}

The macrotetrolide ionophore antibiotic 'polynactin' family is composed of both enantiomers of nonactic acid (1), homononactic acid (2) or bishomononactic acid (3) and are assembled from four acids connected in a head-to-tail manner into a 32-membered macrocycle. The macrotetrolide antibiotics nonactin (4), monactin (5), dinactin (6), trinactin $(\mathbf{8})$, tetranactin $(\mathbf{1 0})$, and their homologues macrotetrolides B (13), C (11), D (9) and G (7) (Figure 1) were found in different admixtures and proportions in a variety of Streptomyces species. ${ }^{1,2}$

They display a wide range of biological activities, such as antimicrobial, insecticidal, antifungal and immunosuppressive ${ }^{3}$ or antitumor. ${ }^{4}$ The biological activities of the macrotetrolides are generally traced to their ionophoric properties, ${ }^{5}$ and the potencies of these activities appear to parallel the size of the alkyl substituents of the macrotetrolides: tetranactin is often the most potent member of the family whereas nonactin is generally inactive (this gave rise to its name, that is nonactive). Nonactin is also used for the preparation of ion-selective electrodes. ${ }^{6}$

Although there is no information about the biological activities of macrotetrolides $B-G,{ }^{7}$ it was reported that the $\mathrm{K}^{+}$affinity was found to be highly correlated with the biological activity; for example, the association constant for the $\mathrm{K}^{+}$complex of dinactin is sevenfold higher than that of nonactin. ${ }^{8}$

To study the biological activities of compounds containing bishomononactic acid and also higher homologues, that is tetranactin, macrotetrolides $B-G(7,9,11,13)$, and nonnatural macrocyclic lactones, these compounds were prepared both by cultivation (see above) and by organic synthesis. ${ }^{9}$ Macrotetrolide $\alpha$ was synthesized from two (-)- and two (+)-bishomononactic acids in seven steps ${ }^{10}$ but the relevant papers do not mention any biological effects of this compound. Another problem in organic synthesis contrary of the cultivation is the alternation of $(-)$ - and (+)-nonactic acid; that is, two monomers of $(-)$-nonactic acid and two monomers of $(+)$ nonactic acid assembled to form $(+)-(-)-(+)-(-)$ 32-membered lactone nonactin. This natural nonactin has about 100 -fold stronger antimicrobial activity against Bacillus anthracis, Enterococcus faecalis, Staphylococcus aureus or methicillin-resistant $S$. aureus than the synthetic all(+) or all(-) nonactin. ${ }^{11}$

To prepare sufficient amounts of higher nonactin homologues for further biological studies, we optimized cultivation conditions on a pilot-plant scale including the use of precursor-directed biosynthesis

Institute of Microbiology, Academy of Sciences of the Czech Republic, Prague, Czech Republic

Correspondence: Dr T Řezanka, Institute of Microbiology, Academy of Sciences of the Czech Republic, Videnska 1083, Prague 14220, Czech Republic.

E-mail: rezanka@biomed.cas.cz

This paper is dedicated to Arnold L Demain, one of the world's leading industrial microbiologists, a pioneer in the research of secondary metabolites, a great human being and for many years my best friend. I wish you all the best in the years to come-JS.

Received 24 March 2010; revised 22 June 2010; accepted 4 July 2010; published online 28 July 2010 
<smiles>[2H][C@@H](O)C[C@@H]1CC[C@H]([C@@H](C)C(=O)O)O1</smiles>

$1 \mathrm{R}=\mathrm{Me}$

$2 \mathrm{R}=\mathrm{Et}$

$3 \mathrm{R}=\mathrm{i}-\mathrm{Pr}$

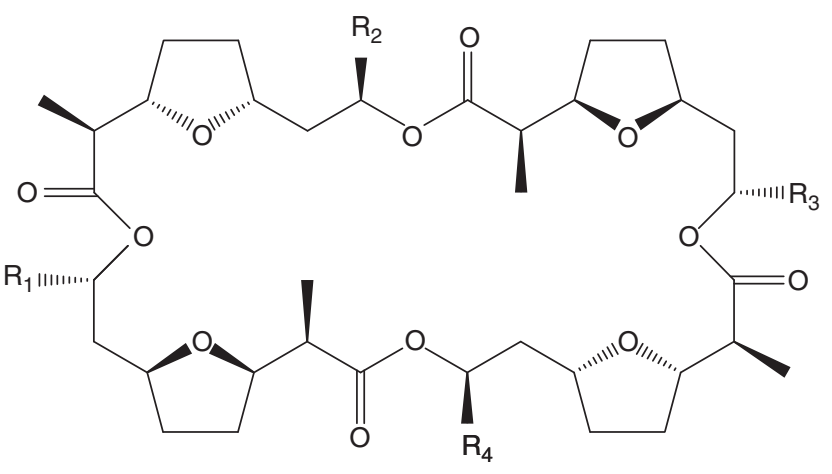

\begin{tabular}{|c|c|c|c|}
\hline No & $\mathrm{R}_{1}$ & $\mathrm{R}_{2}$ & $\mathrm{R}_{3}$ \\
\hline 4 & $\mathrm{Me}$ & $\mathrm{Me}$ & $\mathrm{Me}$ \\
\hline 5 & $\mathrm{Me}$ & $\mathrm{Me}$ & $\mathrm{Me}$ \\
\hline 6 & $\mathrm{Me}$ & Et & $\mathrm{Me}$ \\
\hline$\gamma$ & Et & $\mathrm{Me}$ & $\mathrm{i}-\mathrm{Pr}$ \\
\hline 8 & $\mathrm{Me}$ & $\mathrm{Et}$ & Et \\
\hline 9 & Et & $\mathrm{Me}$ & Et \\
\hline 10 & Et & Et & Et \\
\hline 11 & Et & $\mathrm{Me}$ & i-Pr \\
\hline 12 & $\mathrm{Me}$ & $\mathrm{i}-\mathrm{Pr}$ & $\mathrm{i}-\mathrm{Pr}$ \\
\hline 13 & Et & i-Pr & Et \\
\hline 14 & $\mathrm{Me}$ & Et & $\mathrm{i}-\mathrm{Bu}$ \\
\hline 15 & Et & $\mathrm{i}-\mathrm{Pr}$ & i-Pr \\
\hline 16 & i-Pr & i-Pr & $\mathrm{i}-\mathrm{Pr}$ \\
\hline 17 & Et & i-Bu & i-Bu \\
\hline 18 & i-Bu & $\mathrm{i}-\mathrm{Bu}$ & $\mathrm{i}-\mathrm{Bu}$ \\
\hline
\end{tabular}

Figure 1 Structures of nonactic acid (including two higher homologues) and natural or synthetic macrotetrolides.

(PDB) and identification of metabolites by liquid chromatography (LC)/MS-ESI.

\section{MATERIALS AND METHODS}

\section{Strain and cultivation}

A mutant strain Streptomyces griseus 34/249 obtained by genetic improvement $^{12,13}$ was used. It is deposited in the collection of the Institute of Microbiology (Academy of Sciences of the Czech Republic, Prague). The inoculum was cultivated for $24 \mathrm{~h}$ in a complex medium containing glucose $0.5 \%$, soybean meal $1.5 \%$ and yeast extract $0.5 \%$; the medium (351) in a pilotplant bioreactor was inoculated with 1.751 of vegetative inoculum.

For cultivation, the following complex production medium $\left(\mathrm{gl}^{-1}\right)$ was used: glucose 20, soybean meal 20, glycerol 5, peptone 2, yeast extract 2, beef extract 2, $\mathrm{KH}_{2} \mathrm{PO}_{4} 1, \mathrm{MgSO}_{4} \cdot 7 \mathrm{H}_{2} \mathrm{O} 0.05, \mathrm{CaCO}_{3} 1$ and resin 10 (pH not adjusted). Diaion HP20 styrene-divinylbenzene resin was purchased from Supelco (Prague, Czech Republic). For activation the resin granules were washed in twice the volume of $\mathrm{MeOH}$ and stirred for an hour. Excess $\mathrm{MeOH}$ was decanted, and the wetted resin was washed five times with deionized water. The slurry of the activated resin was filtered and the wet resin was added to liquid medium. In mechanically stirred aerobic tank reactor (75L; Bioengineering AG, Wald, Switzerland) the cultivations were performed for 5 days at $28^{\circ} \mathrm{C}$, aeration rate $0.6 \mathrm{VVM}$ and impeller tip speed $1.9 \mathrm{~m} \mathrm{~s}^{-1}$. The bioreactor vessel was equipped with four baffles and stirred by two radial six-blade Rushton turbines and one axial or radial impeller above them on the same shaft. The samples were collected after 2 days, then at 1-day intervals for 6 days. The cultivation was terminated after 6 days.

Sodium salt of a short-chain fatty acid (propionate, isobutyrate or isovalerate) was added in an amount of $10 \mathrm{mmol}$ per 11 of cultivation medium (that is, $33.6 \mathrm{~g}$ of sodium propionate $(0.35 \mathrm{~mol})$ in 351 broth in a 501 fermentor) every $12 \mathrm{~h}$ from 0 to $72 \mathrm{~h}$ and further in an amount of $5 \mathrm{mmol}$ per 11 of medium from 84 to $108 \mathrm{~h}$ every $12 \mathrm{~h}$. In our study, for instance $85 \mathrm{mmol}$ sodium propionate $(8.16 \mathrm{~g})$ per 11 was added in 10 doses. Jizba et al. ${ }^{13}$ added $8.33 \mathrm{~g}$ sodium propionate per $11(500 \mathrm{mg}$ per $60 \mathrm{ml})$ in a single dose at the beginning of cultivation. The production of the sum of nonactins was $220 \mathrm{mgl}^{-1}$ for $1 \mathrm{gl}^{-1}, 260 \mathrm{mgl}^{-1}$ for $2.5 \mathrm{gl}^{-1}, 285 \mathrm{mgl}^{-1}$ for $5 \mathrm{gl}^{-1}, 310 \mathrm{mgl}^{-1}$ for $10 \mathrm{gl}^{-1}, 300 \mathrm{mgl}^{-1}$ for $15 \mathrm{gl}^{-1}$ and $280 \mathrm{mgl}^{-1}$ for $20 \mathrm{gl}^{-1}$ resin. Optimum resin concentration was therefore $10 \mathrm{gl}^{-1}$ (see above).

\section{HPLC and MS instrumentation}

A 1100 Series LC-mass-selective detector (VL model; Agilent Technologies, Santa Clara, CA, USA) equipped with APCI source and combined with Agilent's 1100 Series autosampler (model G1329A), and thermostatted column compartment (model G1316A) was used for reversed-phase LC/MS separations. The instrument was also equipped with four-solvent (model G1312A with additional two-way low-pressure solvent switching valve) and two-solvent (model G1312A) gradient pumps. Both pumps were connected to the flow path using a T-connector.

Two Hichrom HIRPB-250AM $250 \times 2.1 \mathrm{~mm}$ ID, $5-\mu \mathrm{m}$ phase particle columns were connected in series to obtain a high-efficiency column of approximately 53000 plates per $50 \mathrm{~cm}$. The samples were separated using a gradient solvent program: initial from $80 \% \mathrm{H}_{2} \mathrm{O}-20 \%$ THF with $0.1 \mathrm{M} \mathrm{AcONa}$ to $20 \% \mathrm{H}_{2} \mathrm{O}-80 \%$ THF with $0.1 \mathrm{M} \mathrm{AcONa}$ within $90 \mathrm{~min}$; the composition was returned to the initial conditions over $8 \mathrm{~min}$. A peak threshold of $0.3 \%$ intensity was applied to the mass spectra. The eluent flow rate was $0.25 \mathrm{ml} \mathrm{min}^{-1}$, the column temperature was $28^{\circ} \mathrm{C}$ and the volume of injected sample was $2 \mu$.

The column eluent was introduced into the ESI source and the MS was operated in the positive ion mode (ESI) by applying a voltage of $3000 \mathrm{~V}$ to the capillary and the following set of conditions: nebulizer gas $50 \mathrm{psi}$, drying gas $91 \mathrm{~min}^{-1}$, ESI desolvation temperature was $325^{\circ} \mathrm{C}$, fragmentation voltage $1.0 \mathrm{~V}$, peak width $0.2 \mathrm{~min}$ and monitoring mass range 100-1000 Da. Agilent 1100 Series LC/MSD Trap software Version 4.2 was used.

\section{RESULTS AND DISCUSSION}

\section{Precursor-directed biosynthesis}

In its simplest form, PDB consists in feeding a precursor analogue to wild-type strains of a producing organism and building this unnatural precursor into a new product. This approach thus generates novel structurally diverse microbial secondary metabolites by combining chemical and biological methods. ${ }^{14,15}$ It is effective in generating new analogues of natural products but requires basic knowledge of the cultivation of the producer organism and the target natural product's biosynthetic process. A correct precursor should be used; with a wrong precursor, for example $1 \mathrm{~mm}$ nonactic acid having a furan ring, the production of nonactin was inhibited by more than $90 \%$, no effect on biomass production being found up to the $10 \mathrm{~mm}$ concentration of added precursor. ${ }^{16}$

Another strategy, mutasynthesis, uses mutant microorganisms deficient in a key aspect of the biosynthetic pathway; substitution of the natural precursor with a precursor analogue can again lead to the production of a new natural product. As documented, for example, by Bode et al. ${ }^{17}$ in their study of myxalamid production by myxobacterial mutant strains so manipulated, these strains may eventually exhibit the same or a weaker incorporation of suitable precursors into the 
desirable product than the wild-type strains. Another reason for using PDB is that it can be used without time-consuming genetic manipulations using methods of modern molecular biology.

Because the concentration of a precursor during the fermentation varies in dependence on its dosage intervals, we added into the fermentor adsorbent resin, which keeps the precursor concentration relatively constant by reversibly adsorbing and releasing it. ${ }^{18,19}$ The optimum resin concentration in our experiments was $10 \mathrm{gl}^{-1}$.

\section{Cultivation}

UV mutagenesis of the parent strain of $S$. griseus yielded the strain $34 / 249$ that exhibited predominantly cycloheximide-blocked synthesis, was resistant to glucose repression of morphogenesis, produced lower amounts of peptide antibiotics and increased levels of nonactic acid and its homologues including nonactin and its homologues. ${ }^{20}$

Strain 34/249 was cultivated in a 501 fermentor and production of nonactin homologues was studied by LC/MS. As seen in Figure 1 and Tables 1 and 2, addition of different precursors resulted in the production of different nonactin homologues. As reported previously, ${ }^{12}$ cultivation without precursors provided nonactin as a major product, the proportions of its higher homologues in culture medium decreasing with increasing molecular weight (Figure 2a). Figure 3 shows the results of LC/MS analysis of the broth on cultivation day 6 . The production of the homologues increased up to the fifth day and then it leveled off. A similar situation was found after addition of sodium propionate, isobutyrate and isovalerate (Figures $2 \mathrm{~b}-\mathrm{d}$ ). The addition of the precursors resulted on the one hand in a lowering of both total production and the production of the homologues, on the other hand, it brought about a change in their spectrum (Figures $2 \mathrm{a}-\mathrm{d}$ ). The highest drop in production, observed in our cultivation with sodium isovalerate ( $20 \%$ of control), though sizable, was much less than the $96 \%$ drop in production relative to the wild-type observed by Walczak et al. ${ }^{20}$ with the mutant strain S. griseus $\Delta$ nonKJ.

\section{Identification of macrolide mixture by RP-HPLC/MS-ESI}

The methods currently in use for separation and identification of nonactin and its homologues are HPLC or MS; ${ }^{1}$ for example, C18 RPHPLC, using THF-water gradients with sodium salts solution as chelating agent. ${ }^{21}$ On the basis of RP-HPLC analysis of acetone

Table 1 LC and MS data of macrotetrolides, that is (ionophore+H) ${ }^{+}$

\begin{tabular}{|c|c|c|c|c|c|c|c|c|c|c|}
\hline Name & No & $R^{1}$ & $R^{2}$ & $R^{3}$ & $R^{4}$ & $R T(\min )$ & $(1 / 4+H)^{+}$ & $(2 / 4+H)^{+}$ & $(3 / 4+H)^{+}$ & $(M+H)^{+}$ \\
\hline Nonactin & 4 & $\mathrm{Me}$ & $\mathrm{Me}$ & $\mathrm{Me}$ & $\mathrm{Me}$ & 17.48 & 185 & 369 & 553 & 737 \\
\hline Monactin & 5 & $\mathrm{Me}$ & $\mathrm{Me}$ & $\mathrm{Me}$ & Et & 19.58 & 185,199 & 369,383 & 553,567 & 751 \\
\hline Dinactin & 6 & $\mathrm{Me}$ & Et & $\mathrm{Me}$ & Et & 22.72 & 185,199 & 369,383 & 567,581 & 765 \\
\hline Macrotetrolide G & 7 & Et & $\mathrm{Me}$ & $i-\operatorname{Pr}$ & $\mathrm{Me}$ & 25.30 & $185,199,213$ & 383, 397 & $595,581,567$ & 779 \\
\hline Trinactin & 8 & $\mathrm{Me}$ & Et & Et & Et & 25.87 & 185,199 & 383,397 & 581,595 & 779 \\
\hline Macrotetrolide D & 9 & Et & $\mathrm{Me}$ & Et & $i-\operatorname{Pr}$ & 29.76 & $185,199,213$ & 383,411 & $581,595,609$ & 793 \\
\hline Tetranactin & 10 & Et & Et & Et & Et & 30.46 & 199 & 397 & 595 & 793 \\
\hline Macrotetrolide C & 11 & Et & $\mathrm{Me}$ & $i-\operatorname{Pr}$ & $i-\operatorname{Pr}$ & 35.05 & $185,199,213$ & $383,397,411,425$ & $581,595,623$ & 807 \\
\hline Macrotetrolide & 12 & $\mathrm{Me}$ & $i-\operatorname{Pr}$ & $i-\operatorname{Pr}$ & $i-\operatorname{Pr}$ & 38.76 & 185,213 & 397,425 & 609,637 & 821 \\
\hline Macrotetrolide B & 13 & Et & $i-\operatorname{Pr}$ & Et & $i-\operatorname{Pr}$ & 39.33 & 199,213 & 411 & 609,623 & 821 \\
\hline Isobutyl nonactin analog & 14 & $\mathrm{Me}$ & Et & $i-\mathrm{Bu}$ & $i$-Bu & 44.75 & $185,199,227$ & $383,411,425,453$ & $609,637,651$ & 835 \\
\hline Macrotetrolide & 15 & Et & $i-\operatorname{Pr}$ & $i-\operatorname{Pr}$ & $i-\operatorname{Pr}$ & 45.32 & 199,213 & 411,425 & 623,637 & 835 \\
\hline Macrotetrolide $\alpha$ & 16 & $i-\operatorname{Pr}$ & $i-\operatorname{Pr}$ & $i-\operatorname{Pr}$ & $i-\operatorname{Pr}$ & 52.44 & 213 & 425 & 637 & 849 \\
\hline Isobutyl nonactin analog & 17 & Et & $i$-Bu & $i$-Bu & $i$-Bu & 70.80 & 199,227 & 425,453 & 651,679 & 891 \\
\hline Isobutyl nonactin analog & 18 & $i-\mathrm{Bu}$ & $i-\mathrm{Bu}$ & $i-\mathrm{Bu}$ & $i-\mathrm{Bu}$ & 83.26 & 227 & 453 & 679 & 905 \\
\hline
\end{tabular}

Table 2 LC and MS data of macrotetrolides, that is (ionophore+ $\mathrm{Na})^{+}$

\begin{tabular}{|c|c|c|c|c|c|}
\hline Name & No & $(1 / 4+\mathrm{Na})^{+}$ & $(2 / 4+\mathrm{Na})^{+}$ & $(3 / 4+\mathrm{Na})^{+}$ & $(M+N a)^{+}$ \\
\hline Nonactin & 4 & 207 & 391 & 575 & 759 \\
\hline Monactin & 5 & 207,221 & 391,405 & 575,589 & 773 \\
\hline Dinactin & 6 & 207,221 & 391,405 & 589,603 & 787 \\
\hline Macrotetrolide G & 7 & $207,221,235$ & 405,419 & $617,603,589$ & 801 \\
\hline Trinactin & 8 & 207,221 & 405,419 & 603,617 & 801 \\
\hline Macrotetrolide D & 9 & $207,221,235$ & 405,433 & $603,617,631$ & 815 \\
\hline Tetranactin & 10 & 221 & 419 & 617 & 815 \\
\hline Macrotetrolide C & 11 & $207,221,235$ & $405,419,433,447$ & $603,617,645$ & 829 \\
\hline Macrotetrolide & 12 & 207,235 & 419,447 & 631,659 & 843 \\
\hline Macrotetrolide B & 13 & 221,235 & 433 & 631,645 & 843 \\
\hline Isobutyl nonactin analog & 14 & $207,221,249$ & $405,433,447,475$ & $631,659,673$ & 857 \\
\hline Macrotetrolide & 15 & 221,235 & 433,447 & 645,659 & 857 \\
\hline Macrotetrolide $\alpha$ & 16 & 235 & 447 & 659 & 871 \\
\hline Isobutyl nonactin analog & 17 & 221,249 & 447,475 & 673,701 & 913 \\
\hline Isobutyl nonactin analog & 18 & 249 & 475 & 701 & 927 \\
\hline
\end{tabular}



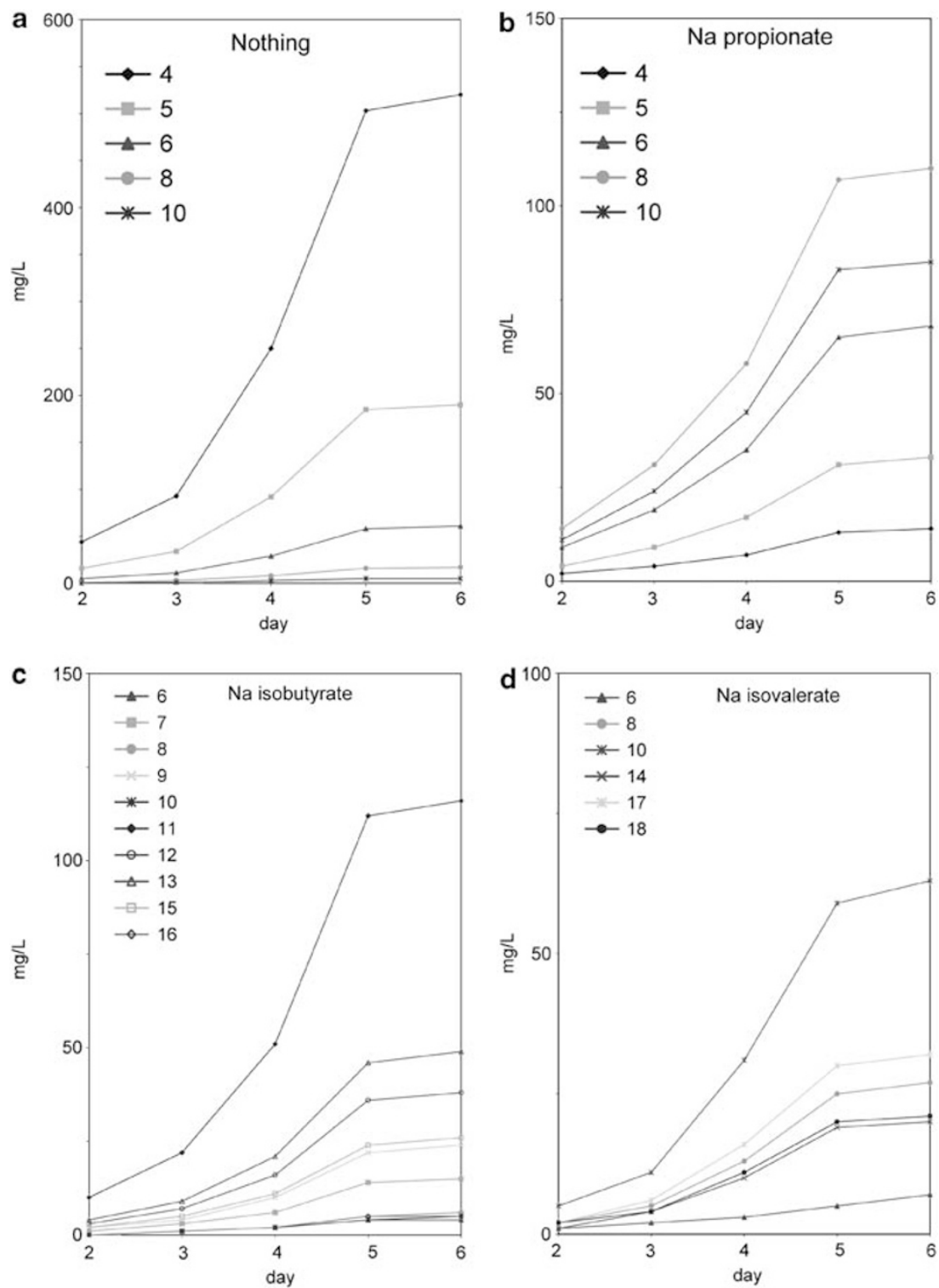

Figure 2 Production of macrotetrolide homologues of nonactin: (a) without addition of sodium salts of short-chain fatty acids, (b) with addition of sodium propionate, (c) with addition of sodium isobutyrate and (d) with addition of sodium isovalerate. Numerals at curves correspond to the designation in Tables 1 and 2.

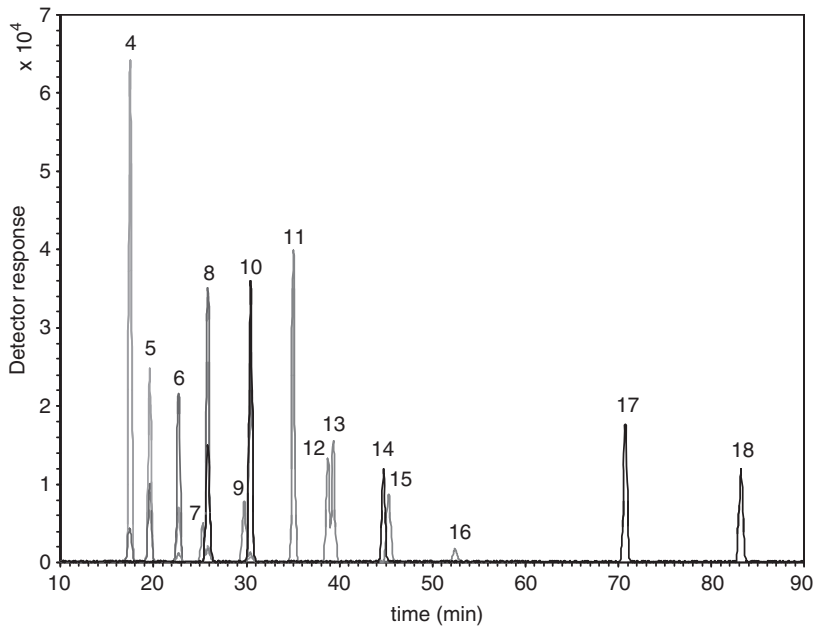

extracts of S. griseus DSM40695 mycelia, which revealed a mixture of nonactin-tetranactin, ${ }^{22}$ we also used $\mathrm{C} 18$ reversed phase with an additional gradient elution with THF-water and with addition of sodium ions. This method separated not only the nonactin homologues differing in a methylene group (see Figure 3) but also the so-called critical pairs, that is macrotetrolide G (7)-trinactin (8), macrotetrolide D (9)-tetranactin (10), macrotetrolide (12)-macrotetrolide B (13) and isobutyl nonactin analogue (14)-macrotetrolide (15) that have the same molecular weight and differ only in $R_{1}-R_{4}$, see Figure 1 and Tables 1 and 2.

Figure 3 Separation of macrotetrolide homologues of nonactin from mutant strain Streptomyces griseus $34 / 249$ by means of RP-HPLC/MS-ESI. For peak assignment, see Table 1 (green, without sodium salts of short-chain fatty acids; blue, sodium propionate was added; red, sodium isobutyrate was added; black, sodium isovalerate was added). A full color version of this figure is available at The Journal of Antibiotics journal online. 
Another possibility of identifying the metabolites is direct flow injection by APCI or ESI-MS. Secondary metabolites such as nonactin were examined with ESI and APCI MS in both positive and negative ion mode. In contrast to positive mode of ESI and APCI, ${ }^{23}$ negative ionization mode did not provide satisfactory results.

Jani et al. ${ }^{24}$ described simultaneous analysis of nonactin and related macrotetrolide homologues using direct infusion LC/MS with ESI. The authors added $\mathrm{K}^{+}$acetate into the medium because, when analyzing mixtures of $\mathrm{NH}_{4}{ }^{+}$adducts, other ions present in the fermentation fluid interfered, resulting in very complex spectra.

Because the broth contains an excess of calcium, though in the form of insoluble carbonate, the doubly charged [ionophore $+\mathrm{Ca}]^{2+}$ complex may present a problem. For example, the ion at $\mathrm{m} / \mathrm{z} 408$ corresponds to loss of $2 \times 184 \mathrm{Da}$ from [nonactin+Ca] ${ }^{2+} .{ }^{25}$ We succeeded in suppressing the formation of doubly charged ions by using an excess of $\mathrm{Na}^{+}$ions throughout the process.

$\mathrm{Na}^{+}$ions were used as a compensating agent for several reasons. First, sodium is monoisotopic in contrast to potassium $\left(93 \%\right.$ of ${ }^{39} \mathrm{~K}$ and $7 \%$ of ${ }^{41} \mathrm{~K}$ ); this feature of potassium makes ESI spectra much more complex. ${ }^{24}$ Second, $\mathrm{Na}^{+}$ions are in all circumstances in a large excess during the cultivation because short-chain acids are present as sodium salts.

In agreement with the paper by Shen and Brodbelt, ${ }^{25}$ and in contrast to earlier studies, ${ }^{2}$ we also did not observe any dehydration of nonactin complexes, presumably reflecting the lack of hydroxyl groups. As shown in Figure 1, all ionophores have a cyclic structure
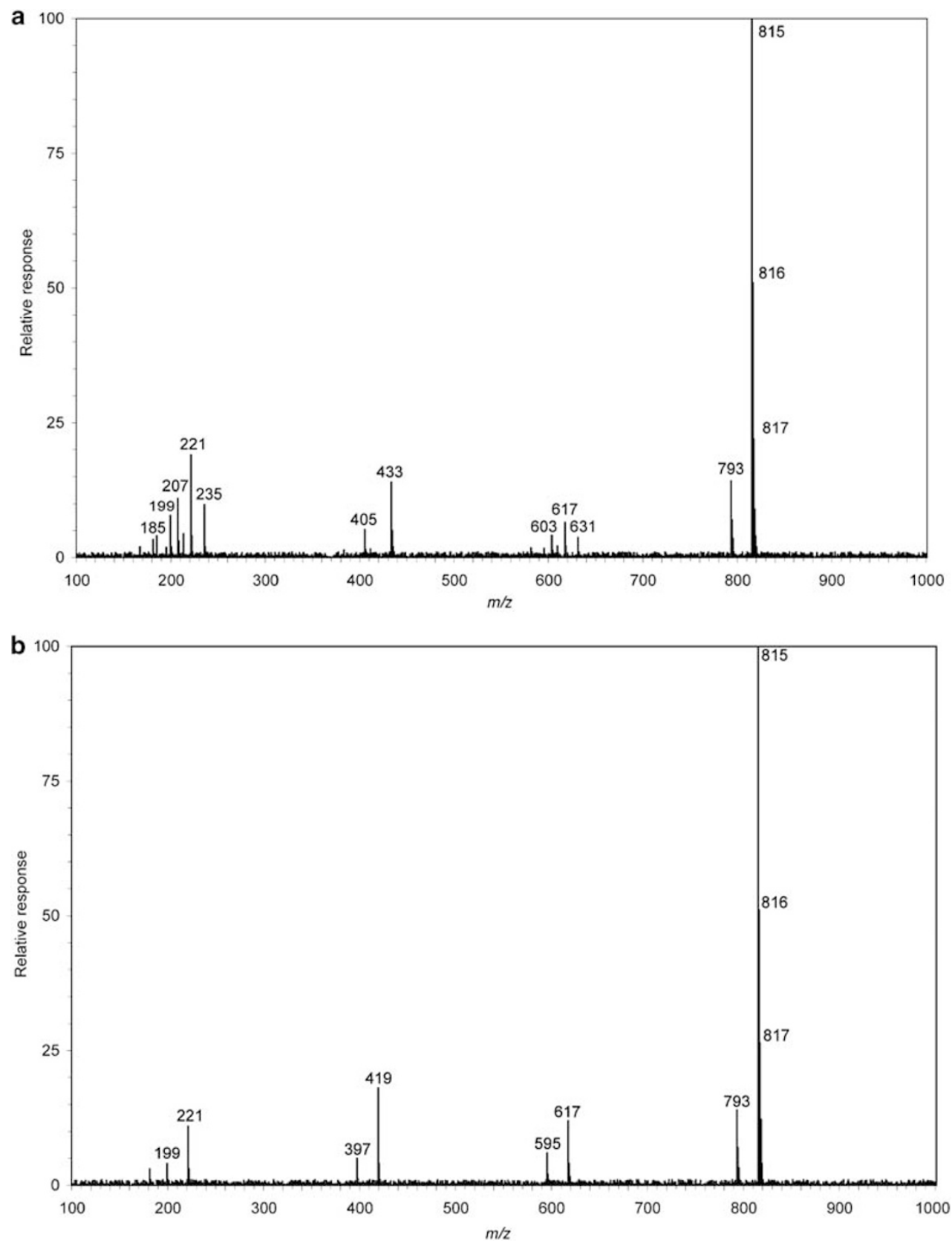

Figure 4 (a) ESI spectrum of macrotetrolide D in peak 9 and its major fragmentation pathway. (b) ESI spectrum of tetranactin in peak 10 and its major fragmentation pathway. 
and therefore multiple covalent bonds must be broken to create observable fragment ions. The nonactin-alkali metal complexes dissociate by a series of losses of nonactic acid (184 Da). For example, the major fragments observed for $[\text { nonactin }+\mathrm{Na}]^{+}$are $\mathrm{m} / \mathrm{z} 575,391$ and 207 (that is, loss of 184 or $2 \times 184$ or $3 \times 184 \mathrm{Da}$ ). One possible proposed pathway is given in literature, ${ }^{25}$ but it is not known whether the products are cyclized or not. Similar pathways likely account for the formation of each of the fragment ions; their numerical values are given in Tables 1 and 2. Figures $4 \mathrm{a}$ and $\mathrm{b}$ also show ESI mass spectra of two compounds from one possible critical pair; that is, compounds 9 and $\mathbf{1 0}$ that have the same summary formula and differ only in the substituents (Me, Et, $i$-Pr, see Figure 1). These values can then serve for identification of individual nonactin homologues and determination of their proportions in the mixture.

\section{CONCLUSIONS}

Pilot-plant scale cultivation in a 501 fermentor using PDB and the mutant strain S. griseus strain 34/249 yielded mixtures selectively enriched in several nonactin homologues according to the precursor used. Though the presence of different precursors usually lowers the overall production, the method can be used for producing novel nonactin homologues.

\section{ACKNOWLEDGEMENTS}

The research was supported by Institutional Research Concept AV 0Z 50200510 and by Project No. 1M06011 of the Ministry of Education, Youth and Sports of the Czech Republic.

1 Keller-Schlierlein, W. \& Gerlach, H. Macrotetrolides. Fortschr. Chem. Org. Naturst. 26, 161-189 (1968).

2 Jizba, J. et al. Macrotetrolide antibiotics produced by Streptomyces globisporus. Folia Microbiol. 36, 437-443 (1991).

3 Zizka, Z. Biological effects of macrotetrolide antibiotics and nonactic acids. Folia Microbiol. 43, 7-14 (1998).

4 Borrel, M. N., Pereira, E., Fiallo, M. \& Garnier-Suillerot, A. Mobile ionophores are a novel class of P-glycoprotein inhibitors. The effects of ionophores on 49-0-tetrahydropyranyl-adriamycin incorporation in K562 drug-resistant cells. Eur. J. Biochem. 223, 125-133 (1994).

5 Marrone, T. J. \& Merz, K. M. Molecular recognition of potassium ion by the naturally occurring antibiotic ionophore nonactin. Biochemistry 114, 7542-7549 (1992).
6 Buhlmann, P., Pretsch, E. \& Bakker, E. Carrier-based ion-selective electrodes and bulk optodes. 2. Ionophores for potentiometric and optical sensors. Chem. Rev. 98, 1593-1687 (1998).

7 Gerlach, H., Hutter, R., Keller-Schlierlein, W., Seibl, J. \& Zahner, H. Metabolic products of microorganisms. LVIII. New macrotetrolides from actinomycetes. Helv. Chim. Acta 50, 1782-1793 (1967).

8 Izatt, R. M. et al. Thermodynamic and kinetic data for cation-macrocycle interaction. Chem. Rev. 85, 271-339 (1985).

9 Coutable, L., Adil, K. \& Saluzzo, C. Total synthesis of a novel macrotetrolide. Tetrahedron 64, 11296-11303 (2008).

10 Hanadate, T., Kiyota, H. \& Oritani, T. Synthesis of macrotetrolide $\alpha$, a designed polynactin analog composed of (+)- and (-)-bishomononactic acids. Biosci. Biotechnol. Biochem. 65, 2118-2120 (2001).

11 Kusche, B. R., Smith, A. E., McGuirl, M. A. \& Priestley, N. D. Alternating pattern of stereochemistry in the nonactin macrocycle is required for antibacterial activity and efficient ion binding. J. Am. Chem. Soc. 131, 17155-17165 (2009).

12 Jizba, J., Hejduková, M. \& Prokinová, E. Stimulation of tetranactin biosynthesis in Streptomyces griseus by propionate and phosphate. Biotechnol. Lett. 19, 295-297 (1997).

13 Jizba, J. \& Skibová, I. Regulation of biosynthesis of pesticidal metabolic complexes in Streptomyces griseus. Folia Microbiol. 39, 119-128 (1994).

14 Thiericke, R. \& Rohr, J. Biological variation of microbial metabolites by precursordirected biosynthesis. Nat. Prod. Rep. 10, 265-289 (1993).

15 Kirschning, A., Taft, F. \& Knobloch, T. Total synthesis approaches to natural product derivatives based on the combination of chemical synthesis and metabolic engineering. Org. Biomol. Chem. 5, 3245-3259 (2007).

16 Kusche, B. R., Phillips, J. B. \& Priestley, N. D. Nonactin biosynthesis: setting limits on what can be achieved with precursor-directed biosynthesis. Bioorg. Med. Chem. Lett. 19, 1233-1235 (2009).

17 Bode, H. B. et al. Mutasynthesis-derived myxalamids and origin of the isobutyryl-CoA starter unit of myxalamid B. ChemBioChem 8, 2139-2144 (2007).

18 Leaf, T. A., Desai, R. P., Licari, P. \& Woo, E. J. Method of producing a compound by fermentation, US Patent 7,459,294 (2008).

19 Singh, M. P. et al. Fermentative production of self-toxic fungal secondary metabolites. J. Ind. Microbiol. Biotechnol. 37, 335-340 (2010).

20 Walczak, R. J., Nelson, M. E. \& Priestley, N. D. Nonactin biosynthesis: Disruption of the polyketide synthase genes, nonKJ, in Streptomyces griseus leads to an overall $96 \%$ decrease in macrotetrolide production, yet a net increase in nonactin analogues which incorporate isobutyrate. J. Am. Chem. Soc. 123, 10415-10416 (2001).

21 Herlt, T. A facile separation of nonactin and its homologues. J. Liq. Chromatogr. Relat. Technol. 20, 1295-1300 (1997).

22 Smith, W. C., Xiang, L. \& Shen, B. Genetic localization and molecular characterization of the nonS gene required for macrotetrolide biosynthesis in Streptomyces griseus DSM40695. Antimicrob. Agents Chemother. 44, 1809-1817 (2000).

23 Zhou, S. \& Hamburger, M. Application of liquid chromatography-atmospheric pressure ionization mass spectrometry in natural product analysis. Evaluation and optimization of electrospray and heated nebulizer interfaces. J. Chromatogr. A 755, 189-204 (1996).

24 Jani, P., Emmert, J. \& Wohlgemuth, R. Process analysis of macrotetrolide biosynthesis during fermentation by means of direct infusion LC-MS. Biotechnol. J. 3, 202-208 (2008).

25 Shen, J. \& Brodbelt, J. S. Characterization of ionophore-metal complexes by infrared multiphoton photodissociation and collision activated dissociation in a quadrupole ion trap mass spectrometer. Analyst 125, 641-650 (2000). 